\title{
EXPLORANDO O CONHECIMENTO MATEMÁTICO ATRAVÉS DAS CONEXÕES POLISSÊMICAS DA ETNOMATEMÁTICA
}

Como editores, nós gostaríamos de agradecer a todos os autores que aceitaram o nosso convite para escreverem para este dossiê intitulado Explorando o Conhecimento Matemático através das Conexões Polissêmicas da Etnomatemática, da Revista ETD: Educação Temática Digital, Faculdade de Educação, da Universidade Estadual de Campinas (UNICAMP). Os 15 autores deste dossiê foram convidados para discutirem as suas ideias e perspectivas e, também, para compartilharem as suas pesquisas sobre as conexões polissêmicas da etnomatemática. Os 8 (oito) artigos que compõem este dossiê representam 04 (quatro) países: Brasil, Grécia, África do Sul e Estados Unidos da América.

Nesta edição especial, nós gostaríamos de enfatizar a importância do matemático e filósofo brasileiro, Ubiratan D’Ambrosio, em relação ao desenvolvimento e evolução da etnomatemática como um programa. Como um dos mais importantes teóricos neste campo de conhecimento e pesquisa, D'Ambrosio oferece encorajamento, liderança e disseminação de novas ideias, conceitos e perspectivas envolvendo a etnomatemática ao redor do mundo e, também, as suas aplicações na educação matemática.

Neste dossiê, discutimos a emergência de importantes terminologias relacionadas com o emergente campo de pesquisa denominado de etno-x. Utilizamos este termo genérico, em que $x$ é uma disciplina particular ou uma área de estudo que pertence à classificação do conhecimento acadêmico enquanto etno se refere às tradições culturais identificadas pelos códigos, condutas, símbolos, mitos e, de uma maneira mais específica, pelos modos por meio dos quais os membros de grupos socioculturais inferem e raciocinam. Um importante objetivo do campo de conhecimento etno-x é promover uma fundamentação teórica capaz de integrar diferentes ramificações das ciências natural e social para outros campos do conhecimento científico.

A fim de abordarmos claramente as inter-relações das fontes do conhecimento local com as formas universais mais amplas, necessitamos entender os conceitos encontrados em conhecimentos tradicionais como as ciências e a matemática, que podem ser apoiados pelas pesquisas em etnociências e etnomatemática. Filosoficamente, o objetivo dessa abordagem é vincular ou unir diferentes culturas numa tentativa de esclarecer e compreender o respeito mútuo entre todas as pessoas. Nesse sentido, o programa etnomatemática visa estimular o desenvolvimento de reflexões mais amplas sobre a natureza do pensamento matemático em ambientes históricos, cognitivos, sociais e culturais; que são motivados pelo entendimento do saber/fazer como conhecimentos construídos pela humanidade em diferentes comunidades, povos, nações e contextos culturais ou étnicos. 
De acordo com esse contexto, em seu artigo intitulado Interações Polissêmicas da Etnomatemática: Uma Visão Geral, Rosa e Orey explicam que as inter-relações locais do conhecimento matemático relacionadas com as diversas áreas do conhecimento acadêmico são importantes para possbilitar uma compreensão mais precisa sobre um determinado campo de estudo em relação às diversas formas da matemática. Essa abordagem é importante para o avanço de uma compreensão investigativa em relação à etnomatemática como um programa de pesquisa e a sua relação polissêmica com outros campos de conhecimento.

Em seu artigo intitulado Etnomatemática: Três Propostas Pedagógicas para a Educação Básica, Bandeira afirma que a difusão da etnomatemática no âmbito da escola fundamental ainda é escassa apesar de suas propostas para a ação pedagógica. Assim, esse autor apresenta três pesquisas direcionadas para o ensino da educação fundamental à luz das concepções dambrosianas da etnomatemática.

Em seu artigo intitulado Etnomatemática e a Busca pela Paz e Justiça Social, D'Ambrosio argumenta que as questões que afetam a sociedade, como, por exemplo, a segurança nacional, a segurança pessoal, a economia, as perturbações sociais e ambientais, as relações entre as nações, as relações entre as classes sociais, o bem-estar das pessoas e a preservação dos recursos naturais e culturais podem ser sintetizados como Paz em suas várias dimensões,como, por exemplo, a paz interna, a paz social, a paz ambiental e a paz militar; que estão intimamente relacionadas.

Em seu artigo intitulado Conceitos Matemáticos de uma Comunidade de Anciãos: Explorando a Conexão entre os Contextos Etnomatemáticos e as Práticas de Sala de Aula, Mosimege argumenta que os membros de uma determinada comunidade possuem uma variedade rica de conhecimento sobre as atividades e os artefatos indígenas. Mesmo que alguns membros dessa comunidade não tenham frequentado a escola formal ou não tenham estudado em um nível significativamente elevado, eles são capazes de utilizar com facilidade os conceitos matemáticos à medida que se envolvem no desenvolvimento das atividades cotidianas.

Em seu artigo intitulado Conversações, Controvérsias e Cálculos em um Chilam Balam de Yucatan Inédito, Tun explora os benefícios e os perigos do contato intercultural no contexto da criação e difusão dos livros de Chilam Balam, que são textos sagrados compilados, principalmente, durante o período colonial, e que eram utilizados pelas comunidades Maias de Yucatan. Esta reprodução do manuscrito inédito de Chilam Balam é uma contribuição única para o campo de estudos Maias e das evidências de sua episteme em relação aos números, ao tempo e ao universo.

Em seu artigo intitulado Confluência Etnomatemática: Intersecção de Visões de Mundo Acadêmica e Nativa, Shockey e Mitchell adotam o conceito de confluência como

(C) ETD-Educação Temática Digital Campinas, SP $\quad$ v.19 $\quad$ n.3 $\quad$ p.584-588 jul./set. 2017


uma metáfora para a compreensão de seu engajamento etnomatemático nos últimos quatorze anos. Em seu trabalho com alunos e professores, esses autores perceberam que a diversidade de significados trazidos para o comprometimento matemático coletivo têm adquirido muitas influências. Assim, a confluência das visões de mundo nativa e acadêmica é o que direciona a história desses autores. Assim, da visão de mundo nativa, eles trazem a riqueza das histórias e das tradições orais.

Em seu artigo intitulado Provocações Polissêmicas da Negociação Fronteiriça, Stathopoulou e Appelbaum consideram a etnomatemática como um caminho para uma educação renovada, tendo como objetivo discutí-la juntamente com as ideias curriculares que exploram o conhecimento matemático em diferentes contextos, bem como a comunicação/tradução entre esses contextos. As fronteiras permeáveis da educação matemática forçam uma tradução que raramente é visível para os envolvidos nesse processo, como, por exemplo, os jovens aprendizes que mudam de escola e de casa para várias comunidades e os professores que tentam traduzir o discurso matemático para culturas escolares que podem acomodar alunos com múltiplas linguagens matemáticas e de aprendizagem.

No último artigo deste dossiê, intitulado Um Conjunto de Ferramentas Matemáticas para a Justiça Generativa; Eglash, Bennett, Drazan, Lachney e Babbitt discutem como a matemática pode contribuir para a justiça social e a sustentabilidade. Esses autores argumentam que a justiça distributiva aborda a pobreza e os problemas a ela relacionados, de cima para baixo, movendo o valor extraído da propriedade privada para a propriedade estatal. Em contraste, a justiça generativa funciona de baixo para cima, substituindo extração de valor e a alienação pela circulação de valores. No caso dos sistemas de conhecimento vernaculares, a colonização por interesses comerciais tem ocorrido, portanto, o desafio é o desenvolvimento de uma alternativa descolonizada.

A fim de elucidar, esclarecer e, talvez, facilitar novas discussões sobre as conexões polissêmicas da etnomatemática, esperamos sinceramente que os leitores possam capturar os pensamentos e os conceitos dos autores em relação à polissemia da etnomatemática. A partir de seus pontos de vista particulares, cada um deles conduziu importantes investigações que foram adicionadas ao crescente corpo do discurso científico desse programa. Consequentemente, quaisquer estudos sobre a etnomatemática e as suas interações polissêmicas representam uma maneira importante para a validação das experiências cotidianas dos alunos, oferecendo-lhes as ferramentas necessárias para que se tornem participantes críticos na sociedade.

Então, existe a necessidade da criação de um novo papel para a matemática em relação à instrução, que pode capacitar os professores para o entendimento do poder e da opressão de um modo mais crítico. Para isso, é importante que os professores considerem a 
influência da cultura e da linguagem no conhecimento matemático dos alunos para que possam descobrir a história, muitas vezes, distorcida e oculta do conhecimento matemático. Esta abordagem forma uma base significante das contribuições da perspectiva dambrosiana, baseada na etnomatemática, para a reconcepção da disciplina de matemática e da sua prática pedagógica.

Nesse contexto, a utilização da metodologia dialógica de Freire é essencial para o desenvolvimento de uma praxis curricular etnomatemática por meio da investigação de outras culturas e línguas que visam a construção de um currículo escolar em conjunto com pessoas de outros grupos culturais, possibilitando o enriquecimento do conhecimento matemático dessas pessoas. Portanto, no contexto dialógico internacional, gostaríamos de ampliar a discussão sobre as possibilidades de inclusão da etnomatemática e de suas interações polissêmicas no currículo matemático para que possamos respeitar a diversidade social e cultural de todas as pessoas em sua busca pela paz. Assim, esta abordagem pode garantir o desenvolvimento da compreensão de nossas diferenças através do diálogo e do respeito visando evitar todo e qualquer tipo de dominação e opressão.

Dessa maneira, a etnomatemática mostra que a matemática é composta por muitas tradições culturais diversas e distintas e não apenas por aquelas que emergiram da região mediterrânea. Por exemplo, as inter-relações do conhecimento local estão relacionadas com as diversas áreas de conhecimento acadêmico, sendo importantes para possibilitar uma compreensão mais precisa sobre um determinado campo de estudo e sua utilização nas inter-relações polissêmicas dos processos matemáticos. Essas inter-relações devem ser claramente abordadas, especialmente, para entendermos os conceitos específicos adquiridos através do conhecimento acadêmico amplamente baseado nas ciências e matemática, pois podem ser apoiados pelas etnosciências e pelos novos campos de pesquisa da etnomodelagem e da etnocomputação para promover o entendimento das relações polissêmicas das interações etnomatemáticas.

Então, o principal objetivo dessa discussão é promover o avanço da pesquisa e da compreensão do contexto dos programas de pesquisa em etnomatemática em diversas localidades do mundo. Como parte desse contexto, os autores deste dossiê foram convidados para discutirem como utiliza as relações polissêmicas da etnomatemática em outros campos de conhecimento e, também, em seus próprios contextos, pois o pensamento matemático, juntamente com a ciência, tem sido influenciado por uma diversidade de características humanas, como, por exemplo, as línguas, as religiões, as morais e as atividades econômicas, sociais e políticas. Conjuntamente com essas características, a humanidade desenvolveu processos lógicos relacionados com a sua necessidade universal de padronizar, quantificar, medir, modelar e explicar; que estão moldados e são operados em distintos contextos sociais e históricos. 
Como cada grupo cultural desenvolveu a sua própria maneira de fazer matemática, essas conexões polissêmicas começaram a representar um determinado sistema cultural, especialmente, pela maneira como os diversos povos quantificam e utilizam os números, empregam as formas e as relações geométricas, medem ou classificam os objetos matemáticos em seu próprio ambiente. Como parte disso, cada grupo cultural desenvolveu o seu próprio caminho para matemizar as suas próprias realidades. Contudo, muitas vezes, a arrogancia científica ocidental representou um desrespeito e uma recusa absoluta no reconhecimento de identidades culturais diversas, colocando em risco os processos de entendimento e compreensão de muitos sistemas culturais não ocidentais.

Esse aspecto propicia o desenvolvimento da confiança e da dignidade dos alunos quando o seu conhecimento anterior é reconhecido, pois essas particularidades não devem ser ignoradas, devendo ser respeitadas quando esses indivíduos entram na escola. Assim, a busca por novas abordagens metodológicas é necessária para que se possa compartilhar, registrar e incluir diversas formas de pensamento, de ideias, de procedimentos e de técnicas matemáticas desenvolvidas em contextos culturais distintos. As interações polissêmicas da etnomatemática podem ser uma das maneiras para alcançarmos esse objetivo.

O foco do programa de etnomatemática está relacionado com o desenvolvimento das competências dos alunos através do estudo das ideias, noções, procedimentos e práticas matemáticas diretamente vinculadas ao seu próprio contexto sociocultural. Numa perspectiva etnomatematica, o estudo do conhecimento matemático relaciona-se com as habilidades que possibilitam o desenvolvimento do raciocínio local, lógico e matemático dos alunos em contextos distintos. Esta abordagem descreve a capacidade de utilização do conhecimento matemático para a resolução de problemas da vida real, aplicando esse conhecimento nas operações numéricas e na interpretação da informação estatística.

Por conseguinte, neste dossiê, os seus autores compartilharam e debateram questões relacionadas com a educação matemática, com as práticas em sala de aula e com o conhecimento matemático de grupos culturais específicos visando a exploração desse conhecimento através da utilização das conexões polissêmicas da etnomatemática, que tem o papel de nos auxiliar no esclarecimento da natureza do conhecimento matemático e, também, do conhecimento em geral.

\section{Ouro Preto, Minas Gerais - Brazil \\ Daniel Clark Orey ${ }^{1}$ Milton Rosa ${ }^{2}$}

\footnotetext{
1 Doctoral Degree in Curriculum and Instruction in Multicultural Education - University of New Mexico. Professor Doutor - Departamento de Educação Matemática - Instituto de Ciências Exatas e Biológicas Universidade Federal de Ouro Preto - Ouro Preto, Minas Gerais - Brasil. Email: oreydc@gmail.com
(C) ETD- Educação Temática Digital
Campinas, SP
v.19 n.3
p. $584-588$
jul./set. 2017 
DOI: $\underline{10.20396 / \text { etd.v19i3.8649769 }}$

Editores do Dossiê

2 Doutorado em Educação, Liderança Educacional - California State University em Sacramento (CSUS) Sacramento, CA - EUA. Professor adjunto do Centro de Educação Aberta e a Distância da Universidade Federal de Ouro Preto (CEAD/UFOP) - Ouro Preto, Minas Gerais - Brasil. Email: milrosa@hotmail.com

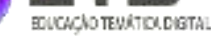

